\title{
RESGATE E ESTABELECIMENTO DE GERMOPLASMA IN VITRO DE MATRIZES DE Eucalyptus cloeziana F. MUELL
}

\author{
Oliveira, L. S. De ${ }^{7}$; Vieira, I. G. ${ }^{8}$; Almeida, C. V. ${ }^{9}$ e Almeida, M. De ${ }^{1}$
}

\section{RESUMO}

A micropropagação apresenta-se como uma alternativa promissora para resgatar e conservar o germoplasma de genótipos de interesse, constituindo-se em alternativa valiosa para a manutenção de coleções de plantas matrizes que podem ser incorporadas em programas de melhoramento de espécies florestais.

Este trabalho objetivou avaliar o efeito dos meios de cultura MS, WPM e JADS no estabelecimento in vitro de gemas epicórmicas de Eucalyptus cloeziana, procedentes de árvores de 26 anos de idade.

A avaliação do experimento foi realizada 25 dias após a introdução in vitro, sendo que o meio de cultura MS apresentou os melhores resultados quanto ao número de gemas induzidas e baixos percentuais de contaminação por fungos e bactérias, constituindo a melhor formulação nutritiva para o resgate e a conservação in vitro destes materiais genéticos.

Palavras chaves: Micropropagação; Eucalyptus; Conservação in vitro; Meio de cultura.

\section{SUMMARY}

Micropropagation is a promising alternative to rescue and conserve the germplasm of interest genotypes, constituting a valuable alternative for the plant collections maintenance of matrices that can be incorporated into breeding programs of forestry species.

This work aimed to evaluate the effect of the medium culture MS, WPM and JADS on the in vitro establishment of the epicormic buds from trees with 25 years old of Eucalyptus cloeziana.

The experiment evaluation was performed 25 days after the in vitro introduction, and the MS medium showed the best results to induce buds number and with low rates of fungi and bacteria contamination, showed the best nutritional formulation for in vitro rescue and conservation of these genetics materials.

Key words: Micropropagation; Eucalyptus; In vitro conservation; Culture medium.

\footnotetext{
${ }^{7}$ Escola Superior de Agricultura Luiz de Queiroz (ESALQ)/Universidade de São Paulo (USP); Brasil. (leandroliveira@usp.br; mdalmeida@usp.br);

8 Instituto de Pesquisa e Estudo Florestais (IPEF); Brasil (Israel@ipef.br);

${ }^{9}$ In Vitro Palm Consultoria. Estudo e Desenv. Biológico Ltda; Brasil (invitropalm@hotmail.com)
} 


\section{INTRODUÇÃO}

Dentre as espécies de Eucalyptus, o E. cloeziana tem despertado o interesse por parte de diversos setores da atividade florestal em razão das características tecnológicas da madeira, de grande durabilidade, de excelente qualidade para serrarias, para a produção de carvão e uso na construção civil (Almeida et al., 2007).

O E. cloeziana tem a particularidade de constituir a única espécie do subgênero Idiogenes. No Brasil, esta espécie foi introduzida há mais de 50 anos (Golfari et al., 1978), apresentando bom crescimento nos locais onde foi plantado, destacando-se como uma das melhores espécies. Embora diferentes procedências dessa espécie tenham sido testadas no país, ainda há carência de maiores estudos quanto à variabilidade destas entre e dentre locais.

Entretanto, ainda residem dificuldades que têm limitado a propagação de forma plena na silvicultura clonal por meio da estaquia, principalmente para o E. cloeziana. Alfenas et al. (2009), afirmam que até o presente momento, esta espécie tem sido considerada de difícil enraizamento, pelos baixos índices de sucesso neste processo, comparada a outras espécies de Eucalyptus.

Esse entrave traz sérias consequências para os programas de melhoramento florestal que se baseiam na multiplicação de genótipos adultos selecionados (Watt et al., 2003).

Nesse contexto, técnicas alternativas como a micropropagação, visando o rejuvenescimento clonal, se constituem como alternativa valiosa para a manutenção de coleções de plantas matrizes que podem ser incorporadas em programas de melhoramento florestal da espécie. A micropropagação via proliferação de gemas axilares tem sido a mais utilizada, em Eucalyptus (Borges et al., 2011), com aplicações comprovadas na área florestal (Xavier et al., 2009).

O estabelecimento in vitro inicia-se com o manejo das plantas matrizes e a seleção dos explantes mais adequados para a micropropagação e finaliza-se com a obtenção de uma cultura adaptada às condições in vitro (Borges et al., 2011). Dessa forma, a desinfestação dos segmentos nodais tem papel relevante para o sucesso do estabelecimento in vitro (Almeida et al., 2009).

Dentre as substâncias utilizadas para a desinfestação dos explantes, o cloro em associação com o etanol é o princípio ativo mais utilizado (Brondani et al., 2009). Nesta fase, a contaminação por fungos e bactérias e a recalcitrância de alguns materiais genéticos tem sido os principais problemas encontrados (George e Debergh, 2008).

Os meios de cultura utilizados na micropropagação fornecem as substâncias essenciais para o crescimento dos tecidos e controlam, em grande parte, o padrão de desenvolvimento in vitro. Na micropropagação de Eucalyptus, o meio de cultura MS (Murashige e Skoog, 1962) tem sido o mais utilizado (Sobrosa e Corder, 2003; Watt et al., 2003; Glocke, et al., 2006; Brondani et al., 2009; Borges et al., 2011). O meio JADS (Correia et al., 1995) também tem sido testado com sucesso em alguns trabalhos de micropropagação com as espécies do gênero (Andrade et al., 2006; Bravo et al., 2008), bem como o meio WPM (Brondani et al., 2012).

Neste contexto, o presente estudo teve como objetivo desenvolver um protocolo para o resgate de material adulto de árvores matrizes de Eucalyptus cloeziana, visando a sua utilização para a conservação ex situ de germoplasma via micropropagação.

\section{MATERIAL E MÉTODOS}

Foram selecionadas 4 matrizes de E. cloeziana, com idade de 26 anos de uma população base de progênies de 25 árvores (CSIRO 14425, Lat. 2618', Long. 152¹8', Alt. $600 \mathrm{~m}$ - Gympie - Queensland), cujas sementes foram coletadas em 1983 na Austrália para o programa da EMBRAPA - Banco de Conservação Genética. 
A seleção das matrizes foi feita de acordo com o diâmetro à altura do peito (DAP), altura, forma do fuste, formato da copa e ausência de doenças. As árvores matrizes selecionadas encontram-se plantadas na Estação Experimental de Ciências Florestais de Anhembi, São Paulo (ESALQ/USP).

O resgate no campo das árvores selecionadas de E. cloeziana foi realizado, conforme relatado por Almeida et al. (2007), por meio da retirada de galhos situados na posição mais baixa da copa, para minimizar os efeitos da idade ontogenética.

Os galhos podados foram seccionados em segmentos (megaestacas) de aproximadamente $0,60 \mathrm{~m}$ de comprimento. Estas foram colocadas em condições de casa de vegetação, sob nebulização, na posição vertical dentro de vasos de polipropileno (3L) preenchidos com areia lavada para a indução de gemas epicórmicas.

O material utilizado como explante foram gemas epicórmicas desenvolvidas nas megaestacas. Antes da coleta das gemas, fez-se a aplicação do fungicida Orthocide $500^{\circledR}$ (Captan $50 \%$ como princípio ativo) a $2,4 \mathrm{~g} \mathrm{~L}^{-1}$.

Gemas epicórmicas, medindo entre 15 e $30 \mathrm{~mm}$, foram coletadas retirando-se as folhas do segundo nó (quando existentes), e reduzindo pela metade as folhas apicais. Após a coleta, os explantes foram imersos em água desionizada e transportados ao laboratório.

Inicialmente os explantes foram lavados em água corrente durante vinte minutos com duas gotas de Twenn 20, procedendo-se em seguida com lavagem em água desionizada autoclavada.

$\mathrm{Na}$ sequência os explantes foram colocados em solução do fungicida contendo $2,4 \mathrm{~g} \mathrm{~L}^{-1}$ de Orthocide ${ }^{\circledR}$, por 15 minutos, ao final dos quais realizou-se três lavagens em água desionizada autoclavada.

Em seguida, os explantes foram imersos em solução de álcool $(70 \%)$ durante 20 segundos, sendo depois, colocados em $\mathrm{NaOCl} 1 \%(\mathrm{v} / \mathrm{v})$ Brilhante ${ }^{\circledR}$ por 5 minutos, adicionados de três gotas Tween 20. Ao final desse tratamento os explantes foram lavados em água desionizada autoclavada por quatro vezes.

Após a desinfestação, os explantes foram inoculados em tubos de ensaio $(10 \times 2,5 \mathrm{~cm})$ contendo $10 \mathrm{~mL}$ de meio de cultura.

Foram utilizados os meios de cultura MS (Murashige e Skoog, 1962), WPM (Lloyd e McCown, 1980) e JADS (Correia et al.,1995) (Tabela 1), adicionados de sacarose $\left(30,0 \mathrm{mg}^{-1} \mathrm{~L}^{-1}\right.$ ) e ágar $\left(4,5 \mathrm{mg} \cdot \mathrm{L}^{-1}\right)$. Os mesmos foram mantidos em câmara de crescimento a $26 \pm 2^{\circ} \mathrm{C}$ e fotoperíodo de 12 horas e irradiância de $50 \pm 2 \mu \mathrm{mol} \mathrm{m}^{-2} \mathrm{~s}^{-1}$, por 30 dias.

O número de gemas formadas por explante, a porcentagem de contaminação fúngica e bacteriana foram avaliados ao fim de 30 dias de subcultivo.

O experimento foi conduzido no delineamento inteiramente casualizado em arranjo fatorial (4x3), avaliando-se quatro clones e três meios de cultura, contendo quatro repetições com seis explantes cada uma das repetições.

Os dados foram analisados por meio das médias e desvio padrão das médias. 
Tabela 1

COMPOSIÇÃO BÁSICA DOS MEIOS DE CULTURA MS, WPM E JADS UTILIZADOS NO

ESTABELECIMENTO IN VITRO DOS QUATRO CLONES DE E. cloeziana.

\begin{tabular}{|c|c|c|c|}
\hline \multirow{2}{*}{ Composição } & \multicolumn{3}{|c|}{ Concentração (mg L $\left.{ }^{-1}\right)$} \\
\hline & $\mathbf{M S}^{(1)}$ & WPM $^{(2)}$ & JADS $^{(3)}$ \\
\hline \multicolumn{4}{|c|}{ Macro e micronutrientes } \\
\hline $\mathrm{NH}_{4} \mathrm{NO}_{3}$ & 1650,0 & 400,0 & 320,0 \\
\hline $\mathrm{KNO}_{3}$ & 1900,0 & - & 809,0 \\
\hline $\mathrm{CaCl}_{2} \cdot 2 \mathrm{H}_{2} \mathrm{O}$ & 440,0 & 96,0 & - \\
\hline $\mathrm{Ca}\left(\mathrm{NO}_{3}\right)_{2} \cdot 4 \mathrm{H}_{2} \mathrm{O}$ & & 556,0 & 1118,0 \\
\hline $\mathrm{KH}_{2} \mathrm{PO}_{4}$ & 170,0 & 170,0 & 408,0 \\
\hline $\mathrm{K}_{2} \mathrm{SO}_{4}$ & & 990,0 & - \\
\hline $\mathrm{MgSO}_{4} \cdot 7 \mathrm{H}_{2} \mathrm{O}$ & 370,0 & 370,0 & 739,5 \\
\hline $\mathrm{MnSO}_{4} \cdot 7 \mathrm{H}_{2} \mathrm{O}$ & 16,9 & 16,9 & 16,9 \\
\hline $\mathrm{CuSO}_{4} \cdot 5 \mathrm{H}_{2} \mathrm{O}$ & 0,025 & 0,25 & 1,25 \\
\hline $\mathrm{ZnSO}_{4} \cdot 7 \mathrm{H}_{2} \mathrm{O}$ & 8,6 & 8,6 & 4,32 \\
\hline $\mathrm{FeSO}_{4} \cdot 7 \mathrm{H}_{2} \mathrm{O}$ & 27,8 & 27,8 & 55,6 \\
\hline $\mathrm{Na}_{2}$ EDTA . $2 \mathrm{H}_{2} \mathrm{O}$ & 37,3 & 37,3 & 74,5 \\
\hline $\mathrm{H}_{3} \mathrm{BO}_{3}$ & 6,2 & 6,2 & 3,1 \\
\hline $\mathrm{Na}_{2} \mathrm{MoO}_{4} \cdot 2 \mathrm{H}_{2} \mathrm{O}$ & 0,25 & 0,25 & 0,15 \\
\hline $\mathrm{CoCl}_{2} \cdot 6 \mathrm{H}_{2} \mathrm{O}$ & 0,025 & - & 0,25 \\
\hline $\mathrm{KI}$ & 0,83 & - & - \\
\hline \multicolumn{4}{|l|}{ Vitaminas } \\
\hline Tiamina $\mathrm{HCl}$ & 0,10 & 1,0 & 5,0 \\
\hline Piridoxina $\mathrm{HCl}$ & 0,50 & 1,0 & 0,5 \\
\hline Ácido Nicotínico & 0,50 & 1,0 & 0,5 \\
\hline Pantotenato de $\mathrm{Ca}^{+2}$ & - & 1,0 & 2,4 \\
\hline Biotina & - & 0,01 & - \\
\hline \multicolumn{4}{|l|}{ Fonte de aminoácido } \\
\hline L-cisteína & - & - & 5,0 \\
\hline Glicina & 2,0 & 1,0 & - \\
\hline \multicolumn{4}{|l|}{ Fonte de carbono } \\
\hline Mio Inositol & 100,0 & 100,0 & 100,0 \\
\hline Sacarose & 30000,0 & 30000,0 & 30000,0 \\
\hline
\end{tabular}

\section{RESULTADOS}

Os resultados demonstraram que os genótipos de E. cloeziana tiveram respostas bastante similares quanto às características avaliadas no estabelecimento in vitro nos diferentes meios de cultura.

Os valores médios da contaminação bacteriana foram menores no meio de cultura MS para os quatro clones, com valores abaixo de 1,5\% (Figura 1).

A contaminação por bactérias teve uma amplitude de variação de 0,75\% (clone 5) a 2,0\% (clone 6), apresentando assim para todos os clones, independentemente do meio de cultura, baixo percentual de contaminação.

Portanto, a contaminação bacteriana não representou um entrave para o estabelecimento da cultura e para a emissão de brotações axilares nos explantes, permitindo a seu desenvolvimento mesmo nos explantes com manifestação bacteriana. 




Barras verticais indicam o desvio padrão das médias.

Figura 1

MÉDIAS DE EXPLANTES CONTAMINADOS POR BACTÉRIAS EM QUATRO CLONES DE E. cloeziana EM TRÊS DIFERENTES MEIOS DE CULTURA (MS, WPM E JADS), AOS 25 DIAS APÓS A INOCULAÇÃO.

A contaminação fúngica ocorreu em menor proporção comparativamente à bacteriana não sendo constatada para os clones 5 e 13 (Figura 2). Os maiores percentuais de contaminação fúngica foram encontrados para o clone 6 no meio JADS (6\%) e WPM (3,8\%). O clone 15 apresentou também contaminação fúngica no estabelecimento in vitro dos explantes nos meios de cultura MS e WPM, porém com percentuais inferiores a 1,8\%.

\section{$\square$ MS $\square$ WPM $\square$ JADS}

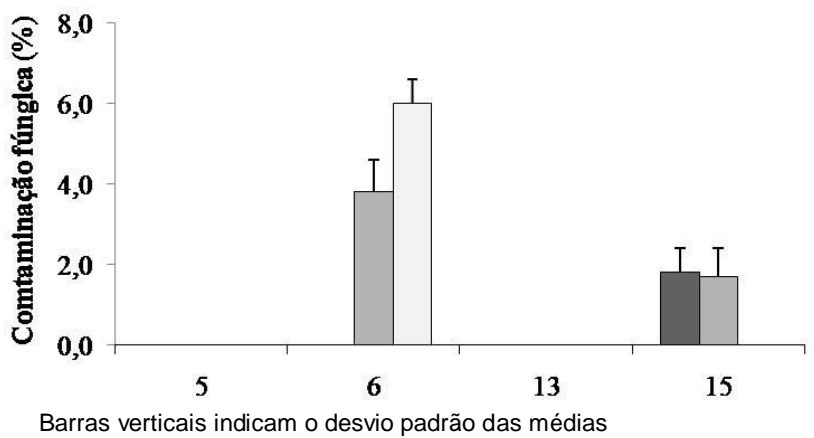

Figura 2

MÉDIAS DE EXPLANTES CONTAMINADOS COM FUNGOS EM QUATRO CLONES DE E. cloeziana EM TRÊS DIFERENTES MEIOS DE CULTURA (MS, WPM E JADS), AOS. 25 DIAS APÓS A INOCULAÇÃO

Em relação ao processo de indução de gemas axilares nos explantes, o número de gemas obtidas foi semelhante entre os clones nos diferentes meios de cultura. Independentemente do clone o número médio de gemas foi maior no meio de cultura MS (Figura 3).

As gemas obtidas nos meios de cultura MS e WPM apresentaram bom vigor vegetativo, sendo aptas para serem transferidas para a fase de multiplicação in vitro. As gemas axilares iniciaram seu desenvolvimento a partir do sétimo dia de cultivo in vitro, sendo observado na região axilar das folhas. 


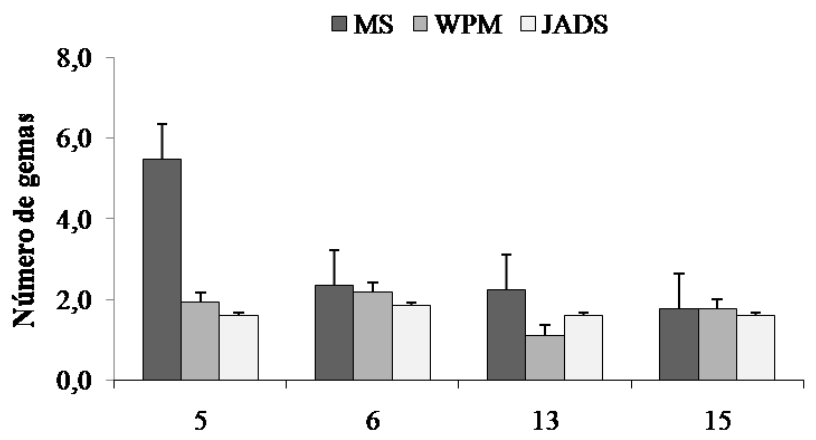

Barras verticais indicam o desvio padrão das médias.

Figura 3

NÚMERO MÉDIO DE GEMAS POR EXPLANTE DE QUATRO CLONES DE Eucalyptus cloeziana EM TRÊS DIFERENTES MEIOS DE CULTURA (MS, WPM E JADS), AOS. 25 DIAS APÓS A INOCULAÇÃO.

\section{DISCUSSÃO}

O presente estudo objetivou a determinação de uma metodologia de resgate e estabelecimento in vitro de clones de E. cloeziana. Para tanto, os resultados demonstraram sucesso no desenvolvimento de um eficiente protocolo de micropropagação clonal via proliferação de gemas axilares não apenas para a conservação de germoplasma destes genótipos, mas também para a sua multiplicação massal e posterior utilização em programas de melhoramento genético da espécie.

O protocolo de desinfestação dos explantes com $\mathrm{NaOCl}$ revelou-se eficiente para o controle da contaminação fúngica e bacteriana para os clones, com exceção do clone 6 , que apresentou o maior percentual de contaminação fúngica, porém, não suficiente para impedir o estabelecimento e multiplicação in vitro. A contaminação fúngica constitui em um dos principais fatores responsáveis pela maior perda de material na fase de estabelecimento in vitro.

Por se tratar de material de proveniente do campo, o risco de ocorrer este tipo de contaminação no estabelecimento in vitro aumenta-se consideravelmente. Dessa forma, a aplicação de fungicida nas brotações epicórmicas ainda na casa de vegetação é recomendada para minimizar esse fator.

Brondani et al. (2009) observaram alta contaminação por fungos $(41,3 \%)$ no estabelecimento in vitro de clones de Eucalyptus benthamii x E. dunnii. Da mesma forma, Almeida et al. (2007) obtiveram alta contaminação por fungos (superior a $25 \%$ ) no estabelecimento in vitro de E. dunnii.

O processo de desinfestação e as condições de cultivo in vitro têm papel preponderante na contaminação bacteriana. Embora a contaminação tenha ocorrido de maneira reduzida, isso não afetou o desenvolvimento das gemas epicórmicas in vitro, o que reforça o sucesso do protocolo de estabelecimento in vitro de material adulto de E. cloeziana. Borges et al. (2011) encontraram elevada contaminação bacteriana para clones híbridos de E. globulus, não afetando, porém, a emissão de brotações axilares.

No presente estudo, as respostas dos clones de E. cloeziana, em relação aos meios de cultura foram bastante similares para as características avaliadas. Sharma e Ramamurthy (2000), estudando o estabelecimento in vitro de Eucalyptus tereticornis, também encontraram grandes variações entre os genótipos estudados. 
O número de gemas induzidas por explante, no estabelecimento in vitro das brotações epicórmicas das árvores matrizes, variou de 1 a 6 . As gemas epicórmicas induzidas na megaestaca desenvolveram-se em aglomerados emergidos em pontos aleatórios, apresentando bom vigor vegetativo. Todavia, ao longo do tempo de permanência na casa de vegetação, observou-se um declínio nesse vigor, o que tornou necessária a introdução in vitro até no máximo 20 dias após a sua emissão. Esse declínio possivelmente ocorreu em razão da competição entre as gemas por reservas.

Dentre os fatores determinantes para o sucesso da micropropagação destaca-se o meio nutritivo, sendo que diversas formulações tem sido empregadas, diferindo entre si, basicamente em relação à concentração de sais. Há uma especificidade dos materiais genéticos ao meio de cultura, sendo que para cada espécie há uma formulação nutritiva ideal. A composição do meio de cultura tem papel fundamental na multiplicação in vitro, uma vez que deve-se levar em conta não apenas os teores totais de nutrientes presentes no meio, mas o quanto destes são disponibilizados para serem absorvidos pela microplanta.

O meio de cultura MS apresentou os melhores resultados constituindo-se na formulação nutritiva mais apropriada para o resgate e o estabelecimento in vitro dos clones de E. cloeziana. $O$ que corrobora os resultados obtidos por Arya et al. (2009), que estabeleceram o meio MS como o melhor para introdução de material adulto de Eucalyptus camaldulensis Dehn $\times$ E. tereticornis Sm e Eucalyptus torelliana F.V. Muell x E. citriodora Hook.

Desta forma, a micropropagação via proliferação de gemas axilares constituiu-se em um método de clonagem com alta fidelidade e estabilidade genética, ao se empregar gemas préformadas, diminuindo os riscos de variação somaclonal.

Portanto, a metodologia mostra-se como alternativa para a conservação e intercâmbio de material genético in vitro de E. cloeziana, além de fornecer subsídios para o estabelecimento de protocolos de conservação e melhoramento de outras espécies do gênero Eucalyptus com igual ou maior valor genético.

\section{CONCLUSÃO}

O meio de cultura MS apresentou os melhores resultados quanto ao número de gemas induzidas e com baixos percentuais de contaminação fúngica e bacteriana, constituindo na melhor formulação nutritiva para o resgate e o estabelecimento in vitro de E. cloeziana.

\section{AGRADECIMENTOS}

À Coordenação de Aperfeiçoamento de Pessoal De Nível Superior (CAPES) pela concessão da bolsa de estudos. Ao Instituto de Pesquisas de Estudos Florestais (IPEF) pela concessão do material genético e apoio logístico.

\section{REFERÊNCIAS}

Alfenas, A. C.; Zauza, E. A. V.; Mafia, R. G. e Assis, T. F. de., 2009. Clonagem e doenças do eucalipto. 2. ed. Viçosa, MG: Editora UFV,. 2009. 500p.

Almeida, F. D.; Xavier, A. e Dias, J. M., 2007. Propagação vegetativa de árvores selecionadas de Eucalyptus cloeziana F. Muell. por estaquia. Revista Arvore, v.31, n.3, p.445-453.

Andrade, W. F.; Almeida, M. e Gonçalves, A. N., 2006. Multiplicação in vitro de Eucalyptus grandis sob estímulo com benzilaminopurina. Pesquisa Agropecuária Brasileira, v.41, n.12, p.1715-1719.

Arya, I. D.; Sharma, S.; Chauhan, S. e Arya, S., 2009. Micropropagation of superior Eucalyptus hybrids FRI-5 (Eucalyptus camaldulensis Dehn x E. tereticornis Sm) and FRI-14 (Eucalyptus torelliana F.V. Muell x E. citriodora Hook): A commercial multiplication and field evaluation. African Journal of Biotechnology, v. 8, n.21, p. 5718-5726. 
Borges, S. R.; Xavier, A.; Oliveira, L. S.; Lopes, A. P. e Otoni, W. C., 2011. Multiplicação in vitro de clones híbridos de Eucalyptus globulus. Revista Árvore, v.35, n.2, 173-182.

Bravo, C. D. V.; Gonçalves, A. N.; Dias, C. T. S. e Vencovsky, R., 2008. Controle genético da regeneração in vitro em progênies de Eucalyptus grandis. Ciência Rural, v.38, n.8, p.2181-2185.

Brondani, G. E.; Dutra, L. F.; Grossi, F.; Wendling, I. e Hornig, J., 2009. Estabelecimento, multiplicação e alongamento in vitro de Eucalyptus benthamii Maiden \& Cambage x Eucalyptus dunnii Maiden. Revista Árvore, v.33, n.1, p.11-19.

Brondani, G. E.; Hansel, F. A.; Dutra, L. F. e Wendling I., 2010. Desinfestação e meio de cultura para o estabelecimento in vitro de segmentos nodais de Liquidambar styraciflua. Floresta, v. 40, n. 3, p.541-554.

Brondani, G. E.; Ondas, H. W. W.; Baccarin, F. J. B.; Gonçalves, A. N. e Almeida, M.. 2012. Micropropagation of Eucalyptus benthamii to form a clonal micro-garden. In Vitro Cellular Development Biology - Plant.

Correia, D.; Gonçalves, A. N.; Couto, H. Y. Z. e Ribeiro, M. C., 1995. Efeito do meio de cultura líquido e sólido no crescimento e desenvolvimento de gemas de Eucalyptus grandis x Eucalyptus urophylla na multiplicação in vitro. Scientia Forestalis, n. 48/49, p. 107-116.

George, E. F. e Debergh, P. C., 2008. Micropropagation: uses and methods. In: George, E. F.; Hall, A. M.; De Klerk, G.-J. (Eds.). Plant propagation by tissue culture: the background. 3.ed. Dordrecht: Springer, v. 1. p.29-64.

Glocke, P. Delaporte, K.; Collins, G. e Sedgley, M., 2006. Micropropagation of juvenile tissue of Eucalyptus erythronema x Eucalyptus stricklandii cv. 'Urrbrae Gem'. In Vitro Cellular \& Developmental Biology - Plant, v.42, n.2, p.139-143.

Golfari, L.; Caser, R. L. e Moura, V. P. G., 1978. Zoneamento ecológico esquemático para reflorestamento no Brasil: 2. aprox. Série técnica. PRODEPEF, v 11, p. 1-110.

Lloyd, G. e McCown, B., 1980. Commercially-feasible micropropagation of mountain laurel, Kalmia latifolia, by use of shoot-tip culture. Combined Proceedings of the International Plant Propagators Society, v. 30, p. 421-427.

Murashige, T. e Skoog, F., 1962. A revised medium for rapid growth with tobacco tissue cultures. Physiologia Plantarum, v.15, p.473-497.

Sharma, S. K. e Ramamurthy, V., 2000. Micropropagation of 4-year-old elite Eucalyptus tereticornis trees. Plant Cell Reports, v. 19, n. 5, p. 511-518.

Sobrosa, R. C. e Corder, M. P. M., 2003. Efeito do genótipo sobre o potencial para produção de gemas e raízes adventícias em Eucalyptus grandis Hill ex Maiden in vitro. Floresta e Ambiente, v.10, n.1, p.58-68.

Watt, M. P. Berjak, P.; Aneliswa, M. e Blakway, F., 2003. In vitro field collection techniques for Eucalyptus micropropagation. Plant Cell, Tissue and Organ Culture, v.75, n.3, p.233-240.

Xavier, A.; Wendling, I. e Silva, R. L., 2009. Silvicultura clonal: princípios e técnicas. Viçosa: UFV, 272 p. 
